\title{
Genetic variants in PARP1 (rs3219090) and IRF4 (rs12203592) genes associated with melanoma susceptibility in a Spanish population
}

Maria Peña-Chilet ${ }^{1 \dagger}$, Maite Blanquer-Maceiras ${ }^{1 \dagger}$, Maider Ibarrola-Villava $^{1}$, Conrado Martinez-Cadenas ${ }^{2}$, Manuel Martin-Gonzalez ${ }^{3}$, Cristina Gomez-Fernandez ${ }^{4}$, Matias Mayor ${ }^{4}$, Juan Antonio Aviles ${ }^{5}$, Ana Lluch and Gloria Ribas ${ }^{1 *}$

\begin{abstract}
Background: Few high penetrance genes are known in Malignant Melanoma (MM), however, the involvement of low-penetrance genes such as MC1R, OCA2, ASIP, SLC45A2 and TYR has been observed. Lately, genome-wide association studies (GWAS) have been the ideal strategy to identify new common, low-penetrance susceptibility loci. In this case-control study, we try to validate in our population nine melanoma associated markers selected from published GWAS in melanoma predisposition.

Methods: We genotyped the 9 markers corresponding to 8 genes (PARP1, MX2, ATM, CCND1, NADSYN1, CASP8, IRF4 and (YP2R1) in 566 cases and 347 controls from a Spanish population using KASPar probes. Genotypes were analyzed by logistic regression and adjusted by phenotypic characteristics.

Results: We confirm the protective role in MM of the rs3219090 located on the PARP1 gene ( $p$-value 0.027). Additionally, this SNP was also associated with eye color ( $p$-value 0.002). A second polymorphism, rs12203592, located on the IRF4 gene was associated with protection to develop MM for the dominant model ( $p$-value 0.037). We have also observed an association of this SNP with both lentigines ( $p$-value 0.014 ) and light eye color ( $p$-value $3.76 \times 10^{-4}$ ). Furthermore, we detected a novel association with rs 1485993, located on the CCND1 gene, and dark eye color ( $p$-value $4.96 \times 10^{-4}$ ). Finally, rs1801516, located on the ATM gene, showed a trend towards a protective role in MM similar to the one firstly described in a GWAS study.

Conclusions: To our knowledge, this is the first time that these SNPs have been associated with MM in a Spanish population. We confirmed the proposed role of rs3219090, located on the PARP1 gene, and rs12203592, located on the IRF4 gene, as protective to MM along the same lines as have previous genome-wide associated works. Finally, we have seen associations between IRF4, PARPI, and CCND1 and phenotypic characteristics, confirming previous results for the IRF4 gene and presenting novel data for the last two, suggesting that pigmentation characteristics correlated with eye color are potential mediators between PARP1 and MM protection.
\end{abstract}

Keywords: Melanoma, GWAs validation, Vitamin D, SNP, Genotyping, Case-control study

\footnotetext{
* Correspondence: gribasdespuig@gmail.com

${ }^{\dagger}$ Equal contributors

'Health Research Institute-INCLIVA, Valencia, Spain

Full list of author information is available at the end of the article
} 


\section{Background}

Few malignant melanoma (MM) susceptibility genes have been described in the literature so far, with only two highpenetrance genes mutated in $20-40 \%$ of familial cases (Cyclin-dependent kinase inhibitor 2 (CDKN2A) and Cyclin-dependent kinase 4 (CDK4)) [1-3]. Seems likely that other genetic factors account for the remaining risk, and that environment should play a role in the etiology as well. It has been suggested that the remaining genetic risks may be due to low-penetrance susceptibility genes, such as the melanocortin-1 receptor $(M C 1 R)$ gene. $M C 1 R$ plays a role in pigmentation in several species; also, genetic variants are associated with pigmentary phenotypes in humans, including red hair, pale skin, freckling, and sun sensitivity $[4,5]$. Indeed, MC1R variants are associated with melanoma susceptibility in several study populations [6-19].

Subsequent studies examined other genes associated with $\mathrm{MM}$. In population-based studies using candidate-gene approaches, a solute carrier 45A2 (SLC45A2) variant was associated with dark hair, dark skin, and protection from melanoma [20-23]. Variations in one of the genes causing oculo-albinism syndrome (OCA2) were associated with melanoma in other studies [24,25], Agouti signaling protein (ASIP) was found to modify melanoma risk in the presence of $M C 1 R$ variants [12], and the Tyrosinase gene (TYR) has variants which code for skin color and are implicated in tanning response [26,27].

Recently, new genome-wide association studies (GWAS) have been conducted and have identified novel genomic loci associated with melanoma $[26,28,29]$. GWAS are the ideal strategy to identify common, low-penetrance susceptibility loci without prior hypotheses about the role of the genes. Some of the associations detected were already known, such as $M C 1 R$ with pigmentation and skin cancer, ASIP, TYR, OCA2, among others. Several novel chromosomal regions, however, have been revealed by using large cohorts of samples created by meta-analyses across studies, like 11q22.3 in Ataxia telangiectasia mutated gene (ATM), 21q22.3 located in Myxovirus resistance 2 gene (MX2) and 2q33.1 in Caspase 8 gene (CASP8) [26].

Taking into account that basal pigmentation and susceptibility to MM differ among populations would be important for determining the relevance of these new markers in more darkly pigmented populations such as the Spanish. Thus, in the present case-control study, we show the analysis of nine SNPs (corresponding to 8 genes: poly (ADP-ribose) polymerase 1 (PARP1), ATM, CASP8, MX2, Cyclin D1 (CCND1), cytochrome P450 family 2 subfamily R polypeptide 1 (CYP2R1), NAD synthetase 1 (NADSYN1) and interferon regulatory factor 4 (IRF4). Six of them were detected by several GWAS studies looking for susceptibility to MM predisposition and an additional three were related to MM and serum levels of vitamin D levels which have been recently studied in relation to sun exposure and their protective role against cancer and other diseases [30,31].

\section{Methods}

\section{Study subjects and data collection}

A total of 566 non-related MM sample cases were recruited from 1st September 2004 up to the present at the departments of dermatology of three different Hospitals in Madrid: Gregorio Marañón University General Hospital, from La Paz University Hospital and Ramón y Cajal University Hospital. A total of 347 volunteer cancer-free control samples, were recruited at the National Research Cancer Center (CNIO) the Madrid College of Lawyers and Gregorio Marañón University General Hospital. All participants were Caucasians of Spanish origin, with the same ethnic background [32].

A standardized questionnaire was used to collect information on pigmentation characteristics such as eye, hair and skin color, number of nevi, presence of solar lentigines, sun exposure habits and presence of childhood sunburns. Sun exposure data consists of an estimation of the frequency (occasionally, always or never) of chronic sun exposure (due to daily work outdoors) and occasional sun exposure (corresponding to sporadic, weekend or holiday exposure), plus the use of sunscreen. Fitzpatrick's classification of skin type, tumor localization, Breslow index (deep index) and personal or family history of cancer was extracted from the medical record of cases only. (Categorization of these variables as well as the distribution of the Spanish population sampled are shown in Additional file 1).

All study subjects gave informed consent, and the study was approved by the Ethics Committee of the Gregorio Marañón General University Hospital.

Genomic DNA from cases and controls was isolated from peripheral blood lymphocytes and diluted to a final solution of $50 \mathrm{ng} / \mu \mathrm{l}$ using the traditional saline method or the DNAzol procedure (Invitrogen, Eugene, OR, USA). DNA concentration was quantified in samples prior to genotyping by using Quant-iT PicoGreen dsDNA Reagent (Invitrogen, Eugene, OR, USA). Further concentration measures were obtained using a Nanodrop 2000 spectrophotometer. Genomic DNA was amplified using the GenomiPhi DNA Amplification Kit (GE Healthcare Bio-Sciences AB, Uppsala, Sweden).

\section{SNPs selection}

Nine SNPs were selected from recent literature using highthroughput platforms in GWAS in order to validate the detected markers in a Spanish population (Table 1). Public databases were used to collect information about SNPs and genes: NCBI http://www.ncbi.nlm.nih.gov and Ensembl http://www.ensembl.org. Details such as MIM code, location, encoded protein, amino acid changes, nucleotide 
changes, minor allele frequency (MAF) from HapMap CEU databases and the context sequence are provided in Additional file 2.

\section{Genotyping assays}

Genotyping was carried out using KASPar technology (KBiosciences, Hoddesdon, UK). The PCR was performed in a total reaction volume of $4 \mu \mathrm{l}$ containing about $10 \mathrm{ng}$ of genomic DNA, with a final concentration of $4 \mathrm{X}$ New KASPar Reaction Mix, $12 \mu \mathrm{m}$ of each Kaspar primer.

The PCR conditions depended on the requirements of each probe according to the manufacturer's indications. The genotype of each sample was determined by measuring final allele-specific fluorescence in the ABI Prism 7900HT Detection System, using the SDS 2.3 software for allelic discrimination (Applied Biosystems, Foster City, USA).

As a quality control measure, we included one no template sample and one sample duplicate per 96-well plate (a total of four per 384-well plate used). Genotypes were provided automatically by the software and were confirmed manually by two different personnel in the laboratory.

\section{Statistical analyses}

For all polymorphisms studied, Fisher's exact test was used both to test for deviations from Hardy-Weinberg equilibrium (HWE) among controls, as well as to compare differences in the minor allele frequency (MAF) distributions between cases and controls. We set as risk factor the minor allele detailed in Table 2. We also performed a CochranArmitage trend test for allelic associations using the complement XLSTAT [33]. Preliminary analyses were performed using SPSSv19 (SPSS, Chicago, IL, USA). All p-values were two-sided, and those less than 0.05 were considered statistically significant. In order to assess associations among genotypes, haplotypes and MM risk, several analyses were performed. Genotype-related odds ratios (ORs), their corresponding 95\% confidence intervals (CIs) and associated $\mathrm{p}$-values were estimated via unconditional logistic regression. This was done for three penetrance models: genotypic, dominant (major homozygotes versus heterozygotes plus minor homozygotes) and recessive (major homozygotes plus heterozygotes versus minor homozygotes).

Multivariate analysis was carried out combining all significant risk factors revealed in Additional file 1, in a multivariate logistic regression to estimate ORs, 95\% CI and p-values. To assess the association of phenotypic characteristics with melanoma, the same logistic regression analyses were performed. To assess the mediation we performed logistic regression analyses using $\mathrm{R}$ (http://www.R-project.org) [34], based on the indications given at http://davidakenny.net/cm/mediate.htm. Known risk factors for MM (eye color, hair color, lentigines, and childhood sunburns) were evaluated for potential confounding effects by including them in multivariate analyses with each significant associated SNP.

\section{Functional analyses}

We used the Haploview v4.2 tool from the HapMap webpage, in order to analyze linkage disequilibrium blocks for SNPs in the PARP1 gene in order to know the frequencies of each haplotype in our population and HapMap populations from Northern Europe (CEU) and Tuscany Italians (TSI). We try to asses possible functional implications of

Table 1 Previous published genome wide association studies considered in the present study

\begin{tabular}{llllllr}
\hline \multicolumn{1}{c}{ A) Published studies of association with Melanoma } & & & & \\
\multicolumn{1}{c}{ Study } & Gene & SNP & Allele & OR & p-value & MM association \\
\hline MacGregor et al. 2011 & PARP1 & rs3219090 & A & 0.82 & $9.5 \times 10^{-7}$ & Protective \\
\hline Barrett et al. 2011 & ATM & rs1801516 & A & 0.79 & $4.80 \times 10^{-7}$ & Protective \\
\cline { 2 - 7 } & CASP8 & rs13016963 & A & 1.18 & $5.68 \times 10^{-7}$ & Risk \\
\cline { 2 - 7 } & MX2 & rs45430 & G & 0.85 & $5.60 \times 10^{-7}$ & Protective \\
\cline { 2 - 7 } & CCND1 & rs1485993 & A & 1.19 & $4.15 \times 10^{-7}$ & Risk \\
\hline Duffy et al. 2010 & IRF4 & rs12203592 & C & 1.15 & $4 \times 10^{-3}$ & Protective \\
\hline
\end{tabular}

B) Previous studies of association with Vitamin D levels

\section{Published Data}

[VitD] $<75 \mathrm{nmol} / \mathrm{L}$ levels

$[$ VitD] $<50 \mathrm{nmol} / \mathrm{L}$ levels

\begin{tabular}{cccccccc}
\hline Study & Gene & SNP & Allele & OR (Cl 95\%) & p-value & OR (Cl 95\%) & p-value \\
\hline Wang et al. 2011 & CYP2R1 & rs10741657 & A & $1.21(1.45-1.29)$ & $9.4 \times 10^{-11}$ & $1.06(1.00-1.13)$ & 0.06 \\
\hline & NADSYN1 & rs7944926 & A & $1.21(1.14-1.29)$ & $4.1 \times 10^{-10}$ & $1.21(1.14-1.29)$ & $4.7 \times 10^{-9}$ \\
\hline & NADSYN1 & rs12785878 & G & - & - & - \\
\hline
\end{tabular}

[VitD] means concentration of vitamin D on plasma. 
Table 2 Allelic frequencies in Spanish cases and controls

\begin{tabular}{|c|c|c|c|c|c|c|c|}
\hline Gene & SNP & Minor allele & p-HWE & MAF Controls & MAF Cases & $\mathrm{p}$-value & trend $^{*}$ \\
\hline PARPI & rs3219090 & $A$ & 0.27 & 0.329 & 0.275 & 0.023 & 0.028 \\
\hline CASP8 & rs13016963 & $A$ & 0.98 & 0.414 & 0.399 & 0.542 & 0.561 \\
\hline$M \times 2$ & rs45430 & G & 0.93 & 0.380 & 0.392 & 0.624 & 0.603 \\
\hline CYP2R1 & rs10741657 & A & 0.16 & 0.378 & 0.381 & 0.891 & 0.867 \\
\hline CCND1 & rs1485993 & $\mathrm{T}$ & 0.48 & 0.448 & 0.438 & 0.697 & 0.652 \\
\hline NADSYN1 & rs7944926 & A & 0.27 & 0.355 & 0.333 & 0.363 & 0.392 \\
\hline NADSYN1 & rs12785878 & G & 0.75 & 0.369 & 0.330 & 0.102 & 0.109 \\
\hline ATM & rs1801516 & A & 0.04 & 0.145 & 0.121 & 0.185 & 0.208 \\
\hline IRF4 & rs12203592 & $\mathrm{T}$ & 0.01 & 0.152 & 0.148 & 0.8 & 0.720 \\
\hline
\end{tabular}

p-HWE: p-value obtained for deviation from Hardy-Weinberg Equilibrium. MAF: Minor Allele Frequency. Bold indicates statistically significant results.

*Trend $p$-values are obtained by performing a Cochran-Armitage test for trend.

all the polymorphisms in the genes of interest by using both the online software Pupasuitev3.1 (http://pupasuite.bioinfo. cipf.es) and the web tool "ECR Browser "(http://ecrbrowser. dcode.org/) to establish a comparison between the human genome and those of other animal species in order to analyze whether gene variations studied in this work are located in sequences important to the function of the protein and to search for the phylogenetically conserved regions of such genes as PARP1, ATM and IRF4 genes.

\section{Results}

\section{HWE and Allelic distributions}

All polymorphisms were checked for HWE. Allele frequencies for each SNP and p-values for their comparison between $566 \mathrm{MM}$ cases and 347 individual controls are detailed in Table 2 along with the p-values for the test of departure from Hardy-Weinberg equilibrium among controls. Only two SNPs gave slight departure from HWE rs1801516 in ATM (p-value 0.04) and rs12203592 in IRF4 (p-value 0.01).

Based on unadjusted p-values, we observed evidence of differences in allele frequency for the SNP in the PARP1 gene (rs3219090, p-value 0.023), implicated in DNA repair, Cochran-Armitage test support this association with a p-value of 0.028 . We did not observe differences in the minor allele frequencies between cases and controls for any other SNP. Data are shown in Table 2.

\section{Association between Genotypes and Melanoma risk}

Two SNPs were found to be associated with MM susceptibility: rs3219090*A, located on the PARP1 gene and implicated in cell repair, is associated with protection from MM using the genotypic model with OR 0.79, 95\% CI 0.63-0.97; p-value 0.027, and rs12203592*T, located in the IRF4 gene, implicated in the immune response, which is associated with MM risk, when the recessive model is considered with OR 6.28, 95\% CI 1.45-27.13; p-value 0.014 . Due to the small number of minor allele homozygotes forming the risk group in the recessive model, we assumed this could be a spurious association. The same allele rs12203592*T also shows a trend towards protection when considering the dominant model with OR 0.83, 95\% CI 0.61-1.12; p-value 0.2. The SNP rs12785878*G on the NADSYN1 gene, associated previously with Vitamin D levels in plasma [31], is borderline associated with MM susceptibility when dominant model is taken into account, with OR 0.76 , 95\% CI 0.57 1.02 ; p-value 0.065 .

Finally, allele rs $1801516^{*} \mathrm{~A}$, located on the ATM gene, shows a trend towards protection in a similar manner to the published data in the GWAS previously reported [26] (Table 1). We were not, however, able to obtain statistically significant results (p-value 0.2 ). No other association remained statistically significant for any of the studied SNPs. Data is shown in Table 3 and in Table 4.

We performed a multivariate analysis, taking into account phenotypic risk factors such as eye and hair color, solar lentigines and the presence of childhood sunburn, together with candidate SNPs. We verified that hair color, lentigines and childhood sunburn were independently associated with MM. Our SNP most associated with MM protection, rs3219090, maintained the trend (OR 0.82, CI 95\% 0.62-1.07; p-value 0.15). Since this SNP was associated with eye color, a risk factor for MM, we suspected that the association between rs3219090 and MM was actually mediated by the eye color. In order to test for the mediation effect of eye color, we performed a mediation analysis considering as covariates the SNP as well as the eye color. The association between this gene and melanoma was no longer significant after adjustment for eye color (OR 0.81, CI 95\% 0.651.01, p-value 0.066). For the rs12203592 SNP located on the IRF4 gene, we observed a statistically significant result (OR 0.65 CI 95\% 0.44-0.98, p-value 0.037) for the dominant model, reinforcing the trend towards protection found in the non-adjusted analysis. The SNP rs12785878 on the NADSYN1 gene maintained a trend to signification. See adjusted values on Table 4 . 
Table 3 Genotypic analyses of all the SNPs studied and their association with MM susceptibility in Spanish population

\begin{tabular}{|c|c|c|c|c|c|c|c|c|c|}
\hline \multirow[t]{2}{*}{ Gene } & \multirow[t]{2}{*}{ SNP } & \multicolumn{3}{|c|}{ Controls N (\%) } & \multicolumn{3}{|c|}{ Cases N (\%) } & \multicolumn{2}{|c|}{ Association } \\
\hline & & Major homozygotes & Heterozygotes & Minor homozygotes & Major homozygotes & Heterozygotes & Minor homozygotes & OR (Cl 95\%) & p-value \\
\hline PARP1 & rs3219090 & $149(46.4)$ & $133(41.4)$ & 39 (12.1) & $255(53.2)$ & $184(38.4)$ & $40(8.3)$ & $0.79(0.63-0.97)$ & 0.027 \\
\hline ATM & rs1801516 & $232(74.6)$ & $68(21.0)$ & $11(3.5)$ & $349(77.7)$ & $91(20.3)$ & $9(2)$ & $0.83(0.62-1.11)$ & 0.203 \\
\hline CASP8 & rs13016963 & $112(34.3)$ & $158(48.5)$ & $56(17.2)$ & $174(35.5)$ & $241(49.2)$ & $75(15.3)$ & $0.94(0.77-1.15)$ & 0.539 \\
\hline$M \times 2$ & rs45430 & $123(38.3)$ & $152(47.3)$ & 46 (14.3) & $180(37.6)$ & $221(46.2)$ & $77(16.1)$ & $1.05(0.86-1.29)$ & 0.627 \\
\hline CCND1 & rs1485993 & $93(29.5)$ & $162(51.4)$ & $60(19.1)$ & $143(30.7)$ & $237(51)$ & 85 (18.3) & $0.96(0.78-1.18)$ & 0.691 \\
\hline IRF4 & rs12203592 & $242(70.1)$ & $101(29.3)$ & $2(0.6)$ & $398(74)$ & $121(22.5)$ & $19(3.5)$ & $0.97(0.74-1.26)$ & 0.801 \\
\hline CYP2R1 & rs10741657 & $123(40.6)$ & $131(43.2)$ & 49 (16.2) & $172(38.1)$ & $214(47.4)$ & $65(14.4)$ & $1.01(0.82-1.25)$ & 0.893 \\
\hline NADSYN1 & rs7944926 & $138(43)$ & $138(43)$ & $45(14)$ & $210(45.5)$ & $195(42.3)$ & $56(12.1)$ & $0.91(0.74-1.12)$ & 0.380 \\
\hline NADSYN1 & rs12785878 & $130(39.3)$ & $157(47.4)$ & 44 (13.3) & $211(45.9)$ & $194(42.2)$ & 55 (11.9) & $0.84(0.68-1.04)$ & 0.106 \\
\hline
\end{tabular}

Bold indicates statistically significant results.

$\mathrm{N}$ refers to the count of individuals, percentages among the total are indicated between parentheses.

OR (C195\%) means Odds Ratio and its 95\% Confidence Interval.

P-values are calculated via unconditional logistic regression, taking into account the codominant model. 
Table 4 MM associated SNPs with statistically significant associations in any of the three penetrance models analysed

\begin{tabular}{|c|c|c|c|c|c|c|c|}
\hline \multirow{3}{*}{$\begin{array}{l}\text { Gene } \\
\text { PARP1 }\end{array}$} & \multirow{2}{*}{ SNP } & \multirow{2}{*}{\multicolumn{2}{|c|}{ Penetrance model }} & \multicolumn{2}{|c|}{ Non adjusted } & \multicolumn{2}{|c|}{ Adjusted } \\
\hline & & & & \multirow{2}{*}{$\begin{array}{c}\text { OR (Cl 95\%) } \\
0.79(0.63-0.97)\end{array}$} & \multirow{2}{*}{$\begin{array}{c}p \text {-value } \\
0.027\end{array}$} & \multirow{2}{*}{$\begin{array}{c}\text { OR (Cl 95\%) } \\
0.82(0.62-1.07)\end{array}$} & \multirow{2}{*}{$\begin{array}{c}\text { p-value } \\
0.151\end{array}$} \\
\hline & rs3219090 & Codominant & GG/AG/AA & & & & \\
\hline & & Dominant & $G G / A G+A A$ & $0.76(0.57-1.01)$ & 0.059 & $0.80(0.56-1.15)$ & 0.228 \\
\hline & & Recessive & $\mathrm{GG}+\mathrm{AG} / \mathrm{AA}$ & $0.66(0.41-1.05)$ & 0.079 & $0.7(0.38-1.28)$ & 0.246 \\
\hline \multirow[t]{3}{*}{ IRF4 } & rs12203592 & Codominant & $\mathrm{CC} / \mathrm{CT} / \mathrm{TT}$ & $0.97(0.74-1.26)$ & 0.801 & $0.76(0.53-1.08)$ & 0.122 \\
\hline & & Dominant & $\mathrm{CC} / \mathrm{CT}+\mathrm{TT}$ & $0.83(0.61-1.12)$ & 0.214 & $0.65(0.44-0.98)$ & 0.037 \\
\hline & & Recessive & $\mathrm{CC}+\mathrm{CT} / \mathrm{TT}$ & $6.28(1.45-27.13)$ & 0.014 & $4.07(0.83-20.05)$ & 0.084 \\
\hline \multirow[t]{3}{*}{ NADSYN1 } & rs12785878 & Codominant & TT/GT/GG & $0.84(0.68-1.04)$ & 0.106 & $0.83(0.64-1.08)$ & 0.165 \\
\hline & & Dominant & $\Pi \mathrm{T} / \mathrm{GT}+\mathrm{GG}$ & $0.76(0.57-1.02)$ & 0.065 & $0.76(0.53-1.10)$ & 0.142 \\
\hline & & Recessive & $\pi+G T / G G$ & $0.89(0.58-1.35)$ & 0.575 & $0.84(0.49-1.44)$ & 0.522 \\
\hline \multirow[t]{3}{*}{ ATM } & rs1801516 & Codominant & $\mathrm{GG} / \mathrm{AG} / \mathrm{AA}$ & $0.83(0.62-1.11)$ & 0.203 & $0.88(0.61-1.28)$ & 0.504 \\
\hline & & Dominant & $\mathrm{GG} / \mathrm{AG}+\mathrm{AA}$ & $0.84(0.6-1.18)$ & 0.318 & $0.92(0.59-1.41)$ & 0.686 \\
\hline & & Recessive & $\mathrm{GG}+\mathrm{AG} / \mathrm{AA}$ & $0.56(0.23-1.36)$ & 0.198 & $0.53(0.15-1.8)$ & 0.310 \\
\hline
\end{tabular}

Bold indicates statistically significant results

OR (Cl 95\%) means Odds Ratio and its 95\% Confidence Interval.

The results are obtained taking into account three penetrance models: Codominant (major homozygotes versus heterozygotes versus minor homozygotes),

Dominant (major homozygotes versus heterozygotes plus minor homozygotes) and Recessive (major homozygotes plus heterozygotes versus

minor homozygotes).

Adjusted for eye color, hair color, lentigines and childhood sunburn via multivariate analysis by performing logistic regression.

\section{Associations between genotypes and phenotypic characteristics}

We assessed whether the SNPs selected from GWAs studies were associated with various phenotypic characteristics. To carry out this task we used the genotypic, dominant and recessive models for each SNP and their associations with all phenotypes.

We observed strong evidence of association with eye color for 3 SNPs. Two of them, rs3219090 on the PARP1 gene with OR: 0.69 (CI 95\%: 0.54-0.88, p-value 0.002), and rs1485993 on the CCND1 gene with OR 0.561 (CI 95\% 0.41-0.78, p-value $\left.4.96 \times 10^{-4}\right)$, both correlated with dark eye color. The third, rs12203592 on the IRF4 gene, with OR 1.83 (CI 95\% 1.34-2.51, p-value $1.63 \times 10^{-4}$ ) was associated with light eye color.

The rs12203592 SNP on the IRF4 gene with OR 1.61 (CI 95\% 1.16-2.24, p-value 0.005) is correlated with the presence of lentigines. We observed an association with absence of childhood sunburn with the SNP rs12785878 located on the NADSYN1 gene with OR 0.69 (CI 95\% 0.51-0.93, p-value 0.015).

We observed other less robust phenotype correlations for skin color and two SNPs; rs10741657 on the CYP2R1 gene with OR 1.24 (CI 95\% 1-1.54, p-value 0.045) and rs7944926 on the NADSYN1 gene with OR 1.37 (CI 95\% 1.03-1.84, p-value 0.033) were both associated with light skin color. Additionally, we observed two SNPs associated with the number of nevi: rs7944926 on the NADSYN1 gene with an OR of 1.59 (CI 95\% 1.01-2.48, p-value 0.044 ) and the rs1801516 on the ATM gene with an OR of 3.12 (CI 95\% 1.06-9.21, p-value 0.039). All this data is shown in Additional file 3.

\section{Functional and haplotype analysis and association with} melanoma risk

We have previous results for rs1136410 on the PARP1 gene [35], and we have combined them with the current results for rs3219090 on the same gene. We performed haplotype analyses; both SNPs belong to a single block according to the Haploview v4.2 program (data used from HAPMAP_CEU and TSI subset of samples). Three haplotypes were obtained, with "TG" being the majority haplotype at $70 \%$ frequency. When we studied the casecontrol analysis, a trend towards protection for the haplotype "CA", with the homozygotes minor alleles in both positions, is maintained (OR 0.79). Furthermore, we detected that two SNPs at approximately $8 \mathrm{~kb}$ in the 5 'upstream region of the ATG, (rs224984 and rs139755) are in complete LD with the associated rs3219090. When we checked for transcription binding sites in the surrounding sequences of these two SNPs, we observed a likely probability for the presence of the regulatory gene functions of interest. Finally, the functional assessment for the 34 genetic variants in the whole sequence of the PARP1 gene showed a single LD block, and 18 of the SNPs present might be located in phylogenetic conserved regions. Only the minor allele of a nonsynonymous variant (rs1136410, pV762A) is carried in approximately half the haplotypes that carry our genotyped SNP. The results of these analyses indicate that SNP rs3219090 is located in a simple repeats area in intron 13, close to an exon. This region is conserved in the cow (bos taurus), macacus (rhesus macaque) and chimpanzee (pan troglodytes). It acts as an intronic enhancer and might function as a regulator of transcription factors. 
The rs12203592 SNP on the IRF4 gene is located in intron 4, and this region is conserved in the opossum (monodelphis domestica), rat (rattus norvegicus), mouse (mus musculus), dog (canis familiaris), cow (bos taurus), macacus (rhesus macaque) and chimpanzee (pan troglodytes). When studying the complete genomic region of the IRF4 gene, we observed 25 SNPs of which 18 are located in conserved regions, including the genotyped rs12203592; however, only the rs1514346 SNP located in the putative promoter region are not in LD with the genotyped SNP in this study appears to affect the binding to the TFBS ETS1.

The rs1801516 SNP, located on the ATM gene, is located in exon 34 and may disrupt splicing regulation. This SNP is conserved in opossum (monodelphis domestica), rat (rattus norvegicus), mouse (mus musculus), dog (canis familiaris), cow (bos taurus), macacus (rhesus macaque) and chimpanzee (pan troglodytes). When we studied the whole genetic variability of the gene, we observed 12 out of 62 SNPs of a non-synonymous nature, among which was the genotyped rs $1801516 \% \mathrm{~A}$, responsible for the change at position 1853 of the protein that causes an alteration of the common amino acid Asp [D] (negative charge) to a polar residue, Asn [N]. Furthermore, another 35 SNPs seem to be located in conserved regions.

\section{Discussion}

In this case-control study we have analyzed a group of nine SNPs selected from previous GWAS and literature related with MM and/or Vitamin D levels with the intention of validating the results in a Spanish population. These validation studies are important in order to confirm the role of these SNPs in populations with different levels of basic pigmentation and make them more relevant. The study in our population, one from the southern Mediterranean, allowed us to observe two strong associations. Despite being able to detect pigmentation and MM associations with some of the candidates, we could not validate them all, probably due to our modest sample size which may not be sufficiently large enough to detect associations from GWAS which use thousands of samples. It is worth noting that having data on sun exposure habits and phenotypic traits has allowed us to give robustness to our results. In addition, we have been able to find novel pigmentation associations and validate others previously described, thereby providing relevant complement information.

First of all, we would like to highlight the rs3219090 SNP, which is located in intron 13 on the PARP1 gene. This gene codes for a chromatin-associated enzyme, poly-ADP ribosyltransferase, which is implicated in several important cell functions such as DNA repair. PARP1 was studied previously in relation to melanoma $[35,36]$; however, the rs3219090 was firstly detected in a GWAS study [28], and the validation of its protective role to MM predisposition has been confirmed in this study's southern Mediterranean (Spanish) population (p-value 0.027). Furthermore, we observed a novel association with eye color ( $p$-value 0.002) not described elsewhere for rs3219090*A. The melanoma association does not remain significant after performing mediation test with eye color, suggesting that this phenotypic trait could mediate to melanoma susceptibility in this population. Nevertheless, our data maintained the same trend towards protection previously described in the GWAS [29]. Additional functional assessments performed in the current study have shown that the associated SNP could indeed be located in an important region since it is a conserved sequence in mammalian species. Furthermore, two SNPs in complete LD with rs3219090, and which are close to the starting codon, could disrupt the binding sites of several transcription factors. This gene has been related to other diseases like gastric cancer [37], cardiopathies [38], glioblastoma [39], bladder cancer [40] and breast cancer [41]. This association to MM could be very relevant. For example, in a highly drug resistant cancer such as melanoma, a candidate gene with known and available inhibitors could be used as an effective therapy, as is being studied in other cancers [42]. Moreover, mechanisms such as gene silencing can reduce the aggressiveness of $\mathrm{MM}$, further suggesting that this gene may be a possible candidate for future therapy [43].

Second, we confirmed a protective association with rs12203592, located in intron 4 on the IRF4 gene. This gene codes for a protein which belongs to the family of transcription factors. The IRFs are important in the regulation of interferon in response to viral infections, and in the regulation of interferon-inducible genes. This SNP was firstly detected in GWAs with an association for hair color and skin pigmentation [44], followed by an association with tanning phenotype [45]. In spite of its being related to pigmentation, the association of this rs12203592 with MM was not always detected [46]. In our study, rs12203592*T was associated with protection to melanoma (OR 0.65, p-value 0.037) when dominant penetrance model is taken into account. A recently published study suggests that minor allele of this SNP (rs12203592*T) is actually associated with risk of developing skin cancer, including MM [47], nevertheless our study validates the protective association obtained by Duffy et al., where rs $12203592 * \mathrm{C}$ (major allele) was associated with the presence of nevi and a predisposition to melanoma [48]. Although we have not being able to find any association between the presence of nevi and rs12203592, we did detect an association with lentigines [48]. In addition, we obtained a strong correlation with light eye color and this SNP (p-value $1.63 * 10^{-4}$ ). This result points in the same direction as previous works in which this SNP has been associated with human skin and eyes pigmentation and was selected as one of the six 
SNPs used in the IrisPlex (set of SNPs studied together in order to predict eye color) [49]. This SNP was slightly out of HWE (p-value 0.01); however, other SNPs located on pigmentation genes such as SLC45A2 alleles, have shown deviation from HWE in several populations of Caucasian origin. This may be explained by the effects of natural selection on skin color, assortative mating or admixture $[21,50]$. The region around this SNP is conserved in all mammalian species sequenced to date. There are known associations between the IRF4 gene and several diseases, such as rhinitis [51] and chronic lymphocytic leukemia $[52,53]$.

Similarly, we have detected for the first time an association with dark eye color and rs1485993*T located on the $C C N D 1$ gene (p-value $\left.4.96 \times 10^{-4}\right)$. Although six SNPs are used in a multiplex that identifies blue vs non-blue eyes, with high correlation and forensic applications, it is of interest to further analyze this proposed SNP due to the strong association found in our study.

Finally, we would like to highlight that the SNP (rs1801516) located on another gene with repair functions, $A T M$, shows an interesting trend towards a protective role in MM similar to the one described in the first GWAS study [26]. In addition, the SNP is in a region with high sequence conservation for all mammalian species available so far. Moreover, according to an in silico functional analysis performed, it may well be able to regulate several transcription factors. The protein encoded by this gene belongs to the PI3/PI4-kinase family. This protein is an important cell cycle checkpoint kinase, and the closely related kinase ATR are thought to be master controllers of the cell cycle checkpoint signaling pathways required for cell response to DNA damage and for genome stability. As well as being responsible for Ataxia telangiectasia, ATM is also involved in several diseases such as diabetes mellitus type 2 [54], leukemia [55], breast cancer [56] and cervix cancer [57], in which the rs1801516 SNP, has been associated with the risk to develop LSIL (Low grade Squamous Intraepithelial Lesion). Moreover, therapeutic advances have been described, based on ATM inhibitors, which are capable of inducing cell apoptosis in cancer cell killing in Melanoma cases [58]. The fact that PARP1 and ATM genes are involved in cell repair, suggests that DNA repair signaling pathways are an important function in susceptibility to melanoma risk.

\section{Conclusions}

In summary, we detected two associations with MM, rs3219090 on the PARP1 gene (mediated by eye color), and rs12203592, on the IRF4 gene (significant after adjusted by phenotypic traits), both conferring a protective role in MM. In addition, we detected three associations the pigmentary characteristics such as eye color, for PARP1, IRF4 and $C C N D 1$ genes in our study population.

\section{Additional files}

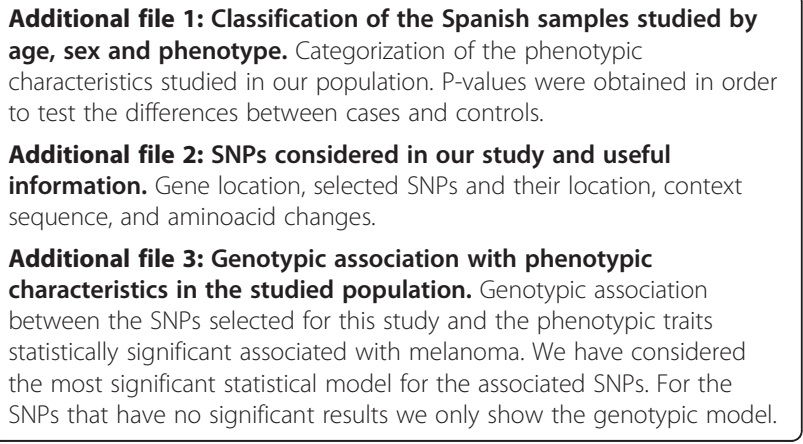

\section{Abbreviations}

MM: Malignant Melanoma; MC1R: Melanocortin 1- receptor; CDK4: Cyclindependent kinase 4; CDKN2A: Cyclin-dependent kinase inhibitor 2A; SLC45A2: Solute carrier 45A2; OCA2: Oculo-albinism syndrome; ASIP: Agouti Signaling Protein; TYR: Tyrosinase gene; PARP1: Poly (ADP-ribose) polymerase; ATM: Ataxia Telangiectasia Mutated; MX2: Myxovirus resistance 2; CCND1: Cyclin D1; NADSYN1: NAD synthetase 1; CYP2R1: Cytochrome P450, family 2, subfamily R, polypeptide 1; CASP8: Caspase 8; IRF4: Interferon regulatory factor 4; GWAS: Genome-Wide Association Study; SNP: Single Nucleotide Polymorphisms; OR: Odds Ratio; MAF: Minor Allele Frequency; PCR: Polymerase Chain Reaction; Cl: Confidence Interval; HWE: HardyWeinberg Equilibrium; LD: Linkage Disequilibrium; TFBS ETS1: Transcription Factor Binding Site; ETS1: v-ets erythroblastosis virus E26 oncogene homolog 1; LSIL: Low grade Squamous Intraepithelial Lesion.

\section{Competing interests}

The authors declare that they have no competing interests.

\section{Authors' contribution}

MPC, MBM, MIV, GR, CMC, MMG, CGF, BC, MM, JAA, and ALL have made substantial contributions to conception and design, or acquisition of data, or analysis and interpretation of data. MPC, MBM, MIV and GR, have been involved in drafting the manuscript or revising it critically for important intellectual content. All authors have given final approval of the version to be published.

\section{Acknowledgments}

This study has been supported by a grant from National Health System Ministry (Institute Carlos III) PI10_0405. MPC is funded by the Generalitat Valenciana Conselleria d'Educació VALi + d program (ACIF/2011/207). MIV is funded by Spanish Ministry of Science and Education under a grant FPI (BES-2008-009234). GR is funded by Spanish Ministry of Health (CP08_00069). We especially thank all the patients and volunteers who gave his consent for the study and the medical staff from Gregorio Marañón, La Paz and Ramón y Cajal Hospitals for collecting the samples. Genotyping with Kaspar was performed at the Unidad Central de Investigación Médica (UCIM) of the Facultad de Medicina from the University of Valencia.

\section{Author details}

${ }^{1}$ Health Research Institute-INCLIVA, Valencia, Spain. ${ }^{2}$ Department of Medicine, University of Castellon Jaume I, Castellon, Spain. ${ }^{3}$ Servicio de Dermatología, Hospital Ramon y Cajal, Madrid, Spain. ${ }^{4}$ Servicio de Dermatología, Hospital Universitario La Paz Hospital, Madrid, Spain. ${ }^{5}$ Servicio de Dermatología, Hospital Gregorio Marañon, Madrid, Spain.

Received: 18 October 2012 Accepted: 20 March 2013 Published: 27 March 2013

\section{References}

1. Goldstein AM, Chidambaram A, Halpern A, Holly EA, Guerry ID, Sagebiel R, Elder DE, Tucker MA: Rarity of CDK4 germline mutations in familial melanoma. Melanoma Res 2002, 12(1):51-55. 
2. Goldstein AM, Landi MT, Tsang S, Fraser MC, Munroe DJ, Tucker MA: Association of MC1R variants and risk of melanoma in melanoma-prone families with CDKN2A mutations. Cancer Epidemiol Biomarkers Prev 2005, 14(9):2208-2212

3. Kefford RF, Newton Bishop JA, Bergman W, Tucker MA: Counseling and DNA testing for individuals perceived to be genetically predisposed to melanoma: a consensus statement of the Melanoma Genetics Consortium. J Clin Oncol 1999, 17(10):3245-3251.

4. Rees JL: Genetics of hair and skin color. Annu Rev Genet 2003, 37:67-90

5. Rees JL: The genetics of sun sensitivity in humans. Am J Hum Genet 2004 75(5):739-751.

6. Bastiaens M, ter Huurne J, Gruis N, Bergman W, Westendorp R, Vermeer BJ, Bouwes Bavinck JN: The melanocortin-1-receptor gene is the major freckle gene. Hum Mol Genet 2001, 10(16):1701-1708.

7. Box NF, Duffy DL, Chen W, Stark M, Martin NG, Sturm RA, Hayward NK MC1R genotype modifies risk of melanoma in families segregating CDKN2A mutations. Am J Hum Genet 2001, 69(4):765-773.

8. Fernandez L, Milne R, Bravo J, Lopez J, Aviles J, Longo M, Benitez J, Lazaro $P$, Ribas G: MC1R: three novel variants identified in a malignant melanoma association study in the Spanish population. Carcinogenesis 2007, 28(8):1659-1664

9. Gerstenblith MR, Goldstein AM, Fargnoli MC, Peris K, Landi MT: Comprehensive evaluation of allele frequency differences of MC1R variants across populations. Hum Mutat 2007, 28(5):495-505.

10. Ibarrola-Villava M, Hu HH, Guedj M, Fernandez LP, Descamps V, BassetSeguin N, Bagot M, Benssussan A, Saiag P, Fargnoli MC, et al: MC1R, SLC45A2 and TYR genetic variants involved in melanoma susceptibility in Southern European populations: Results from a Meta-analysis. Eur $J$ Cancer 2012, 48(14):2183-2191.

11. Kennedy C, ter Huurne J, Berkhout M, Gruis N, Bastiaens M, Bergman W, Willemze R, Bavinck JN: Melanocortin 1 receptor (MC1R) gene variants are associated with an increased risk for cutaneous melanoma which is largely independent of skin type and hair color. J Invest Dermatol 2001 117(2):294-300.

12. Landi MT, Kanetsky PA, Tsang S, Gold B, Munroe D, Rebbeck T, Swoyer J, Ter-Minassian M, Hedayati M, Grossman L, et al: MC1R, ASIP, and DNA repair in sporadic and familial melanoma in a Mediterranean population. J Natl Cancer Inst 2005, 97(13):998-1007.

13. Liboutet M, Portela M, Delestaing G, Vilmer C, Dupin N, Gorin I, Saiag P, Lebbe C, Kerob D, Dubertret L, et al: MC1R and PTCH gene polymorphism in French patients with basal cell carcinomas. J Invest Dermatol 2006, 126(7):1510-1517.

14. Matichard E, Verpillat $P$, Meziani R, Gerard B, Descamps V, Legroux $E_{i}$ Burnouf M, Bertrand G, Bouscarat F, Archimbaud A, et al: Melanocortin 1 receptor $(\mathrm{MC} 1 \mathrm{R})$ gene variants may increase the risk of melanoma in France independently of clinical risk factors and UV exposure. J Med Genet 2004, 41(2):e13.

15. Palmer JS, Duffy DL, Box NF, Aitken JF, O'Gorman LE, Green AC, Hayward NK, Martin NG, Sturm RA: Melanocortin-1 receptor polymorphisms and risk of melanoma: is the association explained solely by pigmentation phenotype? Am J Hum Genet 2000, 66(1):176-186.

16. Raimondi S, Sera F, Gandini S, lodice S, Caini S, Maisonneuve P, Fargnoli MC: MC1R variants, melanoma and red hair color phenotype: a meta-analysis. Int J Cancer 2008, 122(12):2753-2760.

17. Rees J: Plenty new under the sun. J Invest Dermatol 2006, 126(8):1691-1692.

18. Stratigos AJ, Dimisianos G, Nikolaou V, Poulou M, Sypsa V, Stefanaki I, Papadopoulos O, Polydorou D, Plaka M, Christofidou E, et al: Melanocortin receptor-1 gene polymorphisms and the risk of cutaneous melanoma in a low-risk southern European population. J Invest Dermatol 2006, 126(8):1842-1849.

19. Valverde P, Healy E, Sikkink S, Haldane F, Thody AJ, Carothers A, Jackson IJ, Rees JL: The Asp84Glu variant of the melanocortin 1 receptor (MC1R) is associated with melanoma. Hum Mol Genet 1996, 5(10):1663-1666.

20. Fernandez LP, Milne RL, Pita G, Aviles JA, Lazaro P, Benitez J, Ribas G SLC45A2: a novel malignant melanoma-associated gene. Hum Mutat 2008, 29(9):1161-1167.

21. Graf J, Hodgson R, van Daal A: Single nucleotide polymorphisms in the MATP gene are associated with normal human pigmentation variation. Hum Mutat 2005, 25(3):278-284

22. Guedj M, Bourillon A, Combadieres C, Rodero M, Dieude P, Descamps V, Dupin N, Wolkenstein P, Aegerter P, Lebbe C, et al: Variants of the MATP/
SLC45A2 gene are protective for melanoma in the French population. Hum Mutat 2008, 29(9):1154-1160.

23. Nakayama K, Fukamachi S, Kimura H, Koda Y, Soemantri A, Ishida T: Distinctive distribution of AIM1 polymorphism among major human populations with different skin color. J Hum Genet 2002, 47(2):92-94.

24. Duffy DL, Zhao ZZ, Sturm RA, Hayward NK, Martin NG, Montgomery GW: Multiple pigmentation gene polymorphisms account for a substantial proportion of risk of cutaneous malignant melanoma. J Invest Dermatol 2010, 130(2):520-528.

25. Jannot AS, Meziani R, Bertrand G, Gerard B, Descamps V, Archimbaud A Picard C, Ollivaud L, Basset-Seguin N, Kerob D, et al: Allele variations in the OCA2 gene (pink-eyed-dilution locus) are associated with genetic susceptibility to melanoma. Eur J Hum Genet 2005, 13(8):913-920.

26. Barrett JH, Iles MM, Harland M, Taylor JC, Aitken JF, Andresen PA, Akslen LA, Armstrong BK, Avril MF, Azizi E, et al: Genome-wide association study identifies three new melanoma susceptibility loci. Nat Genet 2011, 43(11):1108-1113.

27. Gudbjartsson DF, Sulem P, Stacey SN, Goldstein AM, Rafnar T, Sigurgeirsson B, Benediktsdottir KR, Thorisdottir K, Ragnarsson R, Sveinsdottir SG, et al: ASIP and TYR pigmentation variants associate with cutaneous melanoma and basal cell carcinoma. Nat Genet 2008, 40(7):886-891.

28. Amos Cl, Wang LE, Lee JE, Gershenwald JE, Chen WW, Fang S, Kosoy R, Zhang M, Qureshi AA, Vattathil S, et al: Genome-wide association study identifies novel loci predisposing to cutaneous melanoma. Hum Mol Genet 2011, 20(24):5012-5023.

29. Macgregor S, Montgomery GW, Liu JZ, Zhao ZZ, Henders AK, Stark M, Schmid H, Holland EA, Duffy DL, Zhang M, et al: Genome-wide association study identifies a new melanoma susceptibility locus at 1q21.3. Nat Genet 2011, 43(11):1114-1118

30. Davies JR, Chang YM, Snowden H, Chan M, Leake S, Karpavicius B, Haynes S, Kukalizch K, Randerson-Moor J, Elliott F, et al: The determinants of serum vitamin $D$ levels in participants in a melanoma case-control study living in a temperate climate. Cancer Causes Control 2011, 22(10):1471-1482.

31. Wang TJ, Zhang F, Richards JB, Kestenbaum B, van Meurs JB, Berry D, Kie DP, Streeten EA, Ohlsson C, Koller DL, et al: Common genetic determinants of vitamin D insufficiency: a genome-wide association study. Lancet 2010, 376(9736):180-188.

32. Laayouni $\mathrm{H}$, Calafell F, Bertranpetit J: A genome-wide survey does not show the genetic distinctiveness of Basques. Hum Genet 2010, 127(4):455-458.

33. Guedj M, Wojcik J, Della-Chiesa E, Nuel G, Forner K: A fast, unbiased and exact allelic test for case-control association studies. Hum Hered 2006 61(4):210-221.

34. R Development Core Team: $R$ : A language and environment for statistical computing. Vienna, Austria: R Foundation for Statistical Computing; 2008 http://www.R-project.org. ISBN 3-900051-070

35. Ibarrola-Villava M, Pena-Chilet $M$, Fernandez LP, Aviles JA, Mayor M, MartinGonzalez M, Gomez-Fernandez C, Casado B, Lazaro P, Lluch A, et al: Genetic polymorphisms in DNA repair and oxidative stress pathways associated with malignant melanoma susceptibility. Eur J Cancer 2011, 47(17):2618-2625.

36. Zhang M, Qureshi AA, Guo Q, Han J: Genetic variation in DNA repair pathway genes and melanoma risk. DNA Repair (Amst) 2010, 10(1):111-116.

37. He W, Liu T, Shan Y, Zhu K, Li Y: PARP1 polymorphisms increase the risk of gastric cancer in a Chinese population. Mol Diagn Ther 2012, 16(1):35-42

38. Nagy E, Caidahl K, Franco-Cereceda A, Back M: Increased transcript level of poly(ADP-ribose) polymerase (PARP-1) in human tricuspid compared with bicuspid aortic valves correlates with the stenosis severity. Biochem Biophys Res Commun 2012, 420(3):671-675.

39. Kase M, Vardja M, Lipping A, Asser T, Jaal J: Impact of PARP-1 and DNA-PK expression on survival in patients with glioblastoma multiforme. Radiother Oncol 2011, 101(1):127-131.

40. Teo MT, Landi D, Taylor CF, Elliott F, Vaslin L, Cox DG, Hall J, Landi S, Bishop DT, Kiltie AE: The role of microRNA-binding site polymorphisms in DNA repair genes as risk factors for bladder cancer and breast cancer and their impact on radiotherapy outcomes. Carcinogenesis 2011, 33(3):581-586

41. Fong PC, Boss DS, Yap TA, Tutt A, Wu P, Mergui-Roelvink M, Mortimer $P$ Swaisland H, Lau A, O'Connor MJ, et al: Inhibition of poly(ADP-ribose) polymerase in tumors from BRCA mutation carriers. N Engl J Med 2009, 361(2):123-134. 
42. Kummar S, Chen A, Parchment RE, Kinders RJ, Ji J, Tomaszewski JE, Doroshow JH: Advances in using PARP inhibitors to treat cancer. BMC Med 2012, 10:25

43. Tentori L, Muzi A, Dorio AS, Bultrini S, Mazzon E, Lacal PM, Shah GM, Zhang J, Navarra P, Nocentini G, et al: Stable depletion of poly (ADP-ribose) polymerase-1 reduces in vivo melanoma growth and increases chemosensitivity. Eur J Cancer 2008, 44(9):1302-1314.

44. Han J, Kraft P, Nan H, Guo Q, Chen C, Qureshi A, Hankinson SE, Hu FB, Duffy $\mathrm{DL}$, Zhao ZZ, et al: A genome-wide association study identifies novel alleles associated with hair color and skin pigmentation. PLoS Genet 2008, 4(5):e1000074

45. Nan H, Kraft P, Qureshi AA, Guo Q, Chen C, Hankinson SE, Hu FB, Thomas G, Hoover RN, Chanock S, et al: Genome-wide association study of tanning phenotype in a population of European ancestry. J Invest Dermatol 2009 129(9):2250-2257.

46. Duffy DL, Zhao ZZ, Sturm RA, Hayward NK, Martin NG, Montgomery GW: Multiple pigmentation gene polymorphisms account for a substantial proportion of risk of cutaneous malignant melanoma. J Invest Dermatol 2009, 130(2):520-528.

47. Han J, Qureshi AA, Nan H, Zhang J, Song Y, Guo Q, Hunter DJ: A germline variant in the interferon regulatory factor 4 gene as a novel skin cancer risk locus. Cancer Res 2011, 71(5):1533-1539.

48. Duffy DL, lles MM, Glass D, Zhu G, Barrett JH, Hoiom V, Zhao ZZ, Sturm RA, Soranzo N, Hammond C, et al: IRF4 variants have age-specific effects on nevus count and predispose to melanoma. Am J Hum Genet 2010, 87(1):6-16.

49. Walsh S, Liu F, Ballantyne KN, van Oven M, Lao O, Kayser M: IrisPlex: a sensitive DNA tool for accurate prediction of blue and brown eye colour in the absence of ancestry information. Forensic Sci Int Genet 2010, 5(3):170-180.

50. Soejima M, Koda Y: Population differences of two coding SNPs in pigmentation-related genes SLC24A5 and SLC45A2. Int I Legal Med 2007, 121(1):36-39.

51. Bruhn S, Barrenas F, Mobini R, Andersson BA, Chavali S, Egan BS, Hovig E, Sandve GK, Langston MA, Rogers G, et al: Increased expression of IRF4 and ETS1 in CD4+ cells from patients with intermittent allergic rhinitis. Allergy 2011, 67(1):33-40.

52. Di Bernardo MC, Crowther-Swanepoel D, Broderick P, Webb E, Sellick G, Wild R, Sullivan K, Vijayakrishnan J, Wang Y, Pittman AM, et al: A genomewide association study identifies six susceptibility loci for chronic lymphocytic leukemia. Nat Genet 2008, 40(10):1204-1210.

53. Havelange V, Pekarsky Y, Nakamura T, Palamarchuk A, Alder H, Rassenti L, Kipps T, Croce CM: IRF4 mutations in chronic lymphocytic leukemia. Blood 2011, 118(10):2827-2829.

54. Zhou K, Bellenguez C, Spencer CC, Bennett AJ, Coleman RL, Tavendale R, Hawley SA, Donnelly LA, Schofield C, Groves CJ, et al: Common variants near ATM are associated with glycemic response to metformin in type 2 diabetes. Nat Genet 2010, 43(2):117-120.

55. Britt-Compton B, Lin TT, Ahmed G, Weston V, Jones RE, Fegan C, Oscier DG, Stankovic T, Pepper C, Baird DM: Extreme telomere erosion in ATMmutated and 11q-deleted CLL patients is independent of disease stage. Leukemia 2011, 26(4):826-830

56. Turnbull C, Seal S, Renwick A, Warren-Perry M, Hughes D, Elliott A, Pernet D, Peock S, Adlard JW, Barwell J, et al: Gene-gene interactions in breast cancer susceptibility. Hum Mol Genet 2011, 21(4):958-962.

57. Oliveira S, Ribeiro J, Sousa H, Pinto D, Baldaque I, Medeiros R: Genetic polymorphisms and cervical cancer development: ATM G5557A and p53bp1 C1236G. Oncol Rep 2011, 27(4):1188-1192.

58. Ivanov VN, Zhou H, Partridge MA, Hei TK: Inhibition of ataxia telangiectasia mutated kinase activity enhances TRAIL-mediated apoptosis in human melanoma cells. Cancer Res 2009, 69(8):3510-3519.

\section{doi:10.1186/1471-2407-13-160}

Cite this article as: Peña-Chilet et al:: Genetic variants in PARP1

(rs3219090) and IRF4 (rs12203592) genes associated with melanoma susceptibility in a Spanish population. BMC Cancer 2013 13:160.

\section{Submit your next manuscript to BioMed Central and take full advantage of:}

- Convenient online submission

- Thorough peer review

- No space constraints or color figure charges

- Immediate publication on acceptance

- Inclusion in PubMed, CAS, Scopus and Google Scholar

- Research which is freely available for redistribution

Submit your manuscript at www.biomedcentral.com/submit
Ciomed Central 